\title{
The Effect of Shifting Outer Vertical Symbols on Symbol Error Rate and Average Power for 16QAM
}

\author{
Samir Jasim Mohammed and Ammar Azeez Mohsen \\ Deptartment of Electrical Engineering, Collage of Engineering, University of Babylon, Hillah, Iraq \\ dr_s_j_almuraab@yahoo.com
}

\begin{abstract}
In this study the theoretical formula has been derived for symbol error rate with $\mathrm{E}_{b} \mid \mathrm{N}_{0}$ for $16 \mathrm{QAM}$ standard rectangular form. Having shifted the outer vertical symbols by d energy value to the direction of the original vertical axis, we compute the effect of this shifting of the average power and the probability of error (symbol error rate). Then we compare the analytical results with simulation of 16QAM assuming Additive White Gaussian Noise (AWGN) channel with different value of $\mathrm{d}$.
\end{abstract}

Key words: 16 QAM, AWGN channel, vertucal, shifting, rectanglar, vertical axis

\section{INTRODUCTION}

The QAM scheme was first proposed by C.R. Cahnin 1960 , who described a combined phase and amplitude modulation system (Cahn, 1960). He simply extended phase modulation to the multilevel case by allowing there to be multiple transmitted amplitude at any allowed phase. This had an effect of duplicating the original phase modulation or Phase Shift Keying (PSK) constellation which essentially formed a circle. The next major publication was in 1962, by Campopiano and Glazer (Hancock and Lucky, 1960). Who introduced the square QAM constellation. For $16 \mathrm{QAM}$, there are 16 possible symbols each containing 4 bits, 2 bits for real and 2 bits for the imaginary component, the mapping of the bits into symbols is accordance the gray code which helps to minimize the number of bit errors occurring for every symbol error. Because it is given to a bit assignment where the bit patterns in adjacent symbols only differ by one bit (Bateman, 1999).

Contributions, our contributions can be summarized as follows; theoretical formulas have been derived for 16QAM shifted by d (the outer vertical symbols for slandered 16QAM shifted inside by d value). Then we compare between theoretical results and simulation.

16QAM constellation scheme: In the MQAM scheme, the transmitted signal is represented by the equation below:

$$
s(t)=\sum_{n=-\infty}^{\infty} a_{n} p\left(t-n T_{s}\right) \cos \left(w_{c} t\right)+\sum_{n=-\infty}^{\infty} b_{n} p\left(t-n T_{s}\right) \sin \left(w_{c} t\right)
$$

In which $a_{n}, b_{n}= \pm 1, \pm 3 \cdots \cdots, \pm(\sqrt{M}-1) a_{n}$ and $b_{n}$ are a real and an imaginary part for each symbol where $M$ is the number of symbols in constellation and the carrier frequency is $\mathrm{w}_{\mathrm{c}}$ :

$$
p(t)= \begin{cases}1, & 0 \leq t \leq T_{s} \\ 0, & \text { otherwise }\end{cases}
$$

The adjacent constellation symbols differ by only one bit as shown in Fig. 1. In general, the constellation points for 16QAM modulation can be generated $\mathrm{a}_{\mathrm{n}}+\mathrm{j} \mathrm{b}_{\mathrm{n}}$ as where $a_{n}, b_{n}= \pm 1, \pm 3$ symbols with rectangular constellation diagram are equally spaced and independent and each is represented by aunique combination of amplitude and phase (Glover and Grant, 2010). To simplify the analysis for standardand shifted constellation, the

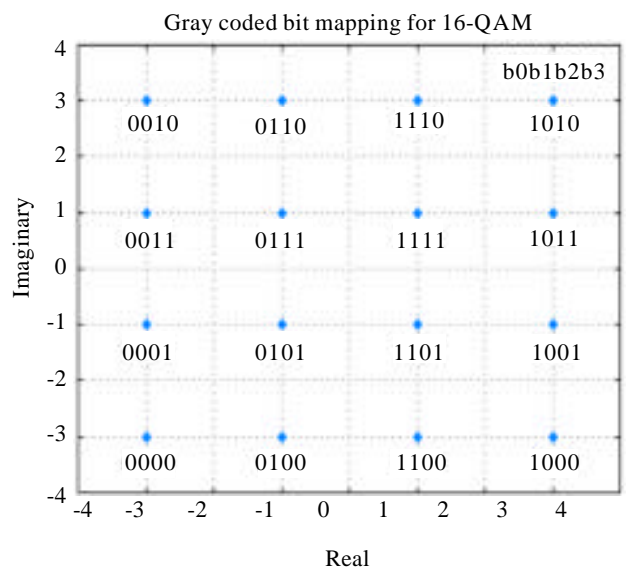

Fig. 1: Gray code bit mapping for 16QAM

Corresponding Author: Samir Jasim Mohammed, Deptartment of Electrical Engineering, Collage of Engineering, University of Babylon, Hillah, Iraq, dr_s_j_almuraab@yahoo.com 


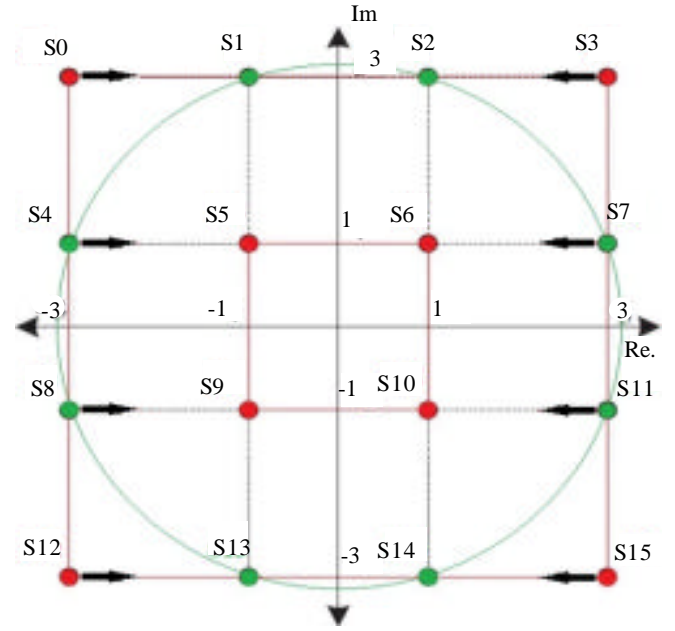

Fig. 2: Standard16QAM and the direction of shifting

symbols have been divided to groups where the interior small square distribution $\left(\mathrm{S}_{5}, \mathrm{~S}_{6}, \mathrm{~S}_{9}, \mathrm{~S}_{10}\right)$ (4 symbols red colour as $\mathrm{S}_{5}$ group). The circler symbols distribution $\left(\mathrm{S}_{1}\right.$, $\left.\mathrm{S}_{2}, \mathrm{~S}_{4}, \mathrm{~S}_{7}, \mathrm{~S}_{8}, \mathrm{~S}_{11}, \mathrm{~S}_{13}, \mathrm{~S}_{14}\right)\left(8\right.$ symbols green colour as $\mathrm{S}_{11}$ group) and outer bigger Square $\left(\mathrm{S}_{0}, \mathrm{~S}_{3}, \mathrm{~S}_{12}, \mathrm{~S}_{13}, \mathrm{~S}_{15}\right)(4$ symbols red colour as $\mathrm{S}_{3}$ group) as shown in Fig. 2 .

\section{MATERIALS AND METHODS}

AWGN channel model: The in-phase and quadrature components of the AWGN is assumed to bestatistically independent, stationary Gaussian noise process with zero mean $\mu=0$ and two-sided Power Spectral density (PDF) of $\mathrm{N} / 2 \mathrm{~W} / \mathrm{Hz}$ :

$$
P(z)=\frac{1}{\sqrt{2 \pi} \sigma} e^{\frac{(z-\mu)^{2}}{2 \sigma^{2}}}
$$

This model is particularly simple to usein the design of optimum receivers and in the detection of signals as zero-mean Gaussian noise is completely characterized by its variance (Chen, 2004), Fig. 3 shows how AWGN corrupts a 16QAM signal with signal-to-noise ratio per bit $\left(\mathrm{E}_{\mathrm{b}} / \mathrm{N}_{0}\right)$ of $8 \mathrm{~dB}$.

Analysis 16QAM standard constellation: To compute the probability of error, we firstly, find the probability of error for the symbols at interior small square ( 4 symbols).

First: We calculate probability of error for $\mathrm{S}_{5}$ symbol (horizontally $\mathrm{P}_{\mathrm{S}_{\mathrm{I}}}$ and $\mathrm{P}_{\mathrm{S}_{\mathrm{V}}}$ vertically) as follows.

Horizontally (PDF): As Fig. 4 shows, to find $\mathrm{P}_{\mathrm{s}_{\mathrm{I}}}$ at $\mathrm{S}_{5}$ is calculated as below:

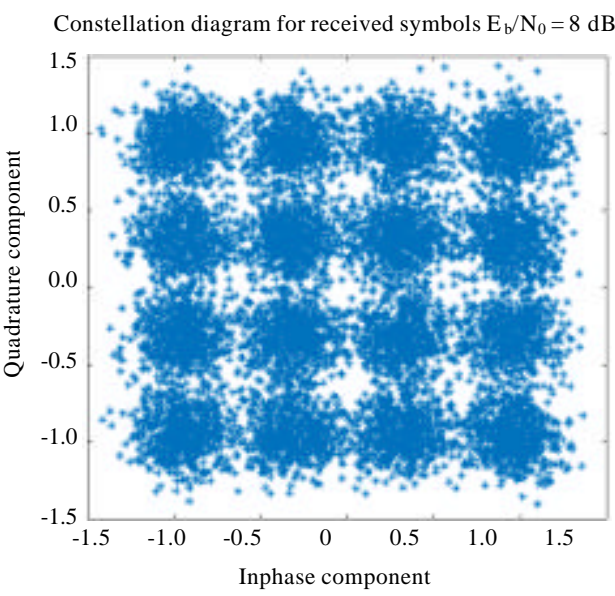

Fig. 3: The scatter plot of 16QAM signal corrupted by AWGN for $=8 \mathrm{~dB}$

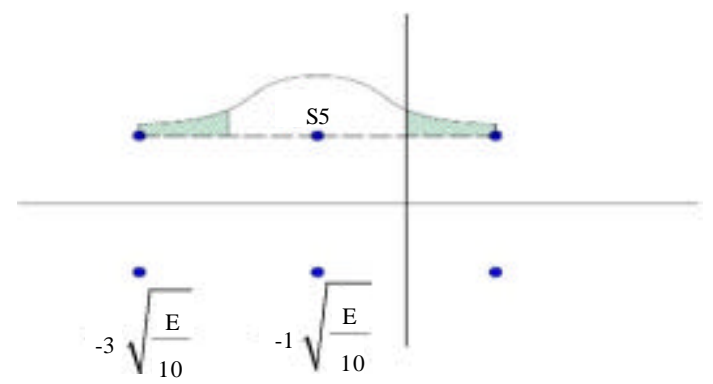

Fig. 4: Horizontal Gaussian (PDF) on S5 symbol

$$
\begin{aligned}
& \mathrm{P}_{\mathrm{S}_{\mathrm{H}}}=\frac{1}{\sqrt{2 \pi} \sigma} \int_{-\infty}^{-2 \sqrt{\frac{E s}{10}}} \mathrm{e}^{\frac{-\left(z \cdot \sqrt{\frac{E s}{10}}\right)^{2}}{2 \sigma^{2}}} \mathrm{dz}+\frac{1}{\sqrt{2 \pi} \sigma} \int_{0}^{\infty} \mathrm{e}^{\frac{-\left(z \cdot \sqrt{\frac{E s}{10}}\right)^{2}}{2 \sigma^{2}}} \mathrm{dz} \\
& \mathrm{P}_{\mathrm{S}_{\mathrm{H}}}=\frac{1}{2} \operatorname{erfc}\left(\sqrt{\frac{\mathrm{Es}}{10 \mathrm{n} 0}}\right)+\frac{1}{2} \operatorname{erfc}\left(\sqrt{\frac{\mathrm{Es}}{10 \mathrm{n} 0}}\right)
\end{aligned}
$$

Vertically (PDF): As Fig. 5 shows, to find $\mathrm{P}_{s_{v}}$ at $\mathrm{S}_{5}$ is calculated as:

$$
\begin{gathered}
\mathrm{P}_{\mathrm{S}_{\mathrm{V}}}=\frac{1}{\sqrt{2 \pi} \sigma} \int_{-\infty}^{0} \mathrm{e}^{\frac{-\left(z \cdot \sqrt{\frac{E s}{10}}\right)^{2}}{2 \sigma^{2}}} \mathrm{dz}+\frac{1}{\sqrt{2 \pi} \sigma} \int_{\sqrt[2 \sqrt{\frac{E S}{10}}]{\infty} \mathrm{e}^{\frac{-\left(z \cdot \sqrt{\frac{E s}{10}}\right)^{2}}{2 \sigma^{2}}} \mathrm{dz}} \\
\mathrm{P}_{\mathrm{S}_{\mathrm{V}}}=\operatorname{erfc}\left(\sqrt{\frac{\mathrm{Es}}{10 \mathrm{n} 0}}\right)
\end{gathered}
$$

The total Probability of error $\mathrm{P}_{\mathrm{S}}$ for Symbol $\mathrm{S}_{5}$ can be found from the total probability for correct symbol $\mathrm{P}_{\mathrm{C}}$ :

$$
\mathrm{P}_{\mathrm{S}}=1-\mathrm{P}_{\mathrm{C}}
$$




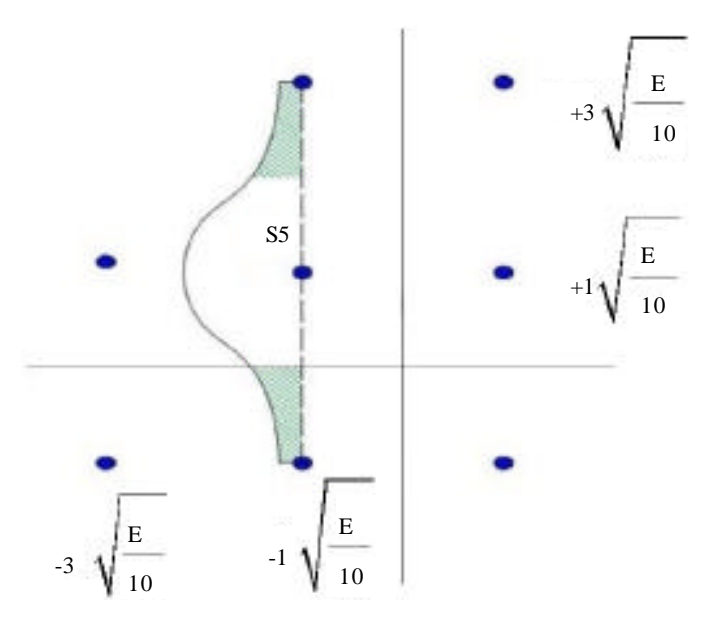

Fig. 5: Vertical Gaussian probability distribution over symbol

where, the Probability of correct $\mathrm{P}_{\mathrm{C}}$ can be computed by multiplying the horizontal correct probability $P_{C_{\mathrm{B}}}$ by the vertical correct probability $P_{c_{v}}$ for the Symbol $S_{5}$ :

$$
\mathrm{P}_{\mathrm{C}}=\mathrm{P}_{\mathrm{C}_{\mathrm{H}}} * \mathrm{P}_{\mathrm{C}_{\mathrm{V}}}=\left(1-\mathrm{P}_{\mathrm{S}_{\mathrm{H}}}\right) *\left(1-\mathrm{P}_{\mathrm{C}_{\mathrm{V}}}\right)
$$

For higher values of Es/n0 by Simplifying the above equation neglecting the final term in it because it is very small, the probability of error can be approximated as:

$$
P_{C}=1-2 \operatorname{erfc}\left(\sqrt{\frac{E s}{10 \mathrm{n} 0}}\right)
$$

Then:

$$
\mathrm{P}_{\mathrm{S}}=1-\mathrm{P}_{\mathrm{C}}=2 \operatorname{erfc}\left(\sqrt{\frac{\mathrm{Es}}{10 \mathrm{n} 0}}\right)
$$

Second: Similarly as first calculation for symbol $\mathrm{S}_{5}$, we can find the probability of error for symbol $\mathrm{S}_{11}$.

Horizontally (PDF): We calculate $\mathrm{P}_{\mathrm{S}_{\mathrm{I}}}$ at $\mathrm{S}_{11}$ as follows:

$$
\begin{aligned}
& \mathrm{P}_{\mathrm{S}_{\mathrm{H}}}=\frac{1}{\sqrt{2 \pi} \sigma} \int_{-\infty}^{\sqrt[2]{\frac{\sqrt{\mathrm{s}}}{10}}} \mathrm{e}^{\frac{\left(\mathrm{z} \cdot \sqrt{\frac{\mathrm{Es}}{10}}\right)^{2}}{2 \sigma^{2}}} \mathrm{dz} \\
& \mathrm{P}_{\mathrm{S}_{\mathrm{H}}}=\frac{1}{2} \operatorname{erfc}\left(\sqrt{\frac{\mathrm{Es}}{10 \mathrm{n} 0}}\right)
\end{aligned}
$$

Vertically (PDF): To find $P_{s_{v}}$ at $S_{11}$ as follows:

$$
\begin{aligned}
& \mathrm{P}_{\mathrm{S}_{\mathrm{V}}}=\frac{1}{\sqrt{2 \pi} \sigma} \int_{-\infty}^{-2 \sqrt{\frac{E s}{10}}} \mathrm{e}^{\frac{\left(z \cdot \sqrt{\frac{E S}{10}}\right)^{2}}{2 \sigma^{2}}} \mathrm{dz}+\frac{1}{\sqrt{2 \pi} \sigma} \int_{0}^{\infty} \mathrm{e}^{\frac{\left(z \cdot \sqrt{\frac{E S}{10}}\right)^{2}}{2 \sigma^{2}}} \mathrm{dz} \\
& \mathrm{P}_{\mathrm{S}_{\mathrm{V}}}=\operatorname{erfc}\left(\sqrt{\frac{\mathrm{Es}}{10 \mathrm{n} 0}}\right)
\end{aligned}
$$

Then, $P_{S}$ at $S_{11}$ is expressed as:

$$
\mathrm{P}_{\mathrm{S}}=1-\mathrm{P}_{\mathrm{C}}
$$

After simplifying the $P_{C}$ equation for higher values of $\mathrm{Es} / \mathrm{n} 0$, the final term is very small, so, ignoring it have little effect on $P_{S}$ equation. So, the probability of error symbol can be approximated as:

$$
\mathrm{P}_{\mathrm{S}}=\frac{3}{2} \operatorname{erfc}\left(\sqrt{\frac{\mathrm{Es}}{10 \mathrm{n} 0}}\right)
$$

Third: The probability of error for symbol $\mathrm{S}_{3}$.

Horizontally (PDF): We compute $\mathrm{P}_{\mathrm{S}_{\mathrm{I}}}$ at $\mathrm{S}_{3}$ as follows:

$$
\begin{aligned}
\mathrm{P}_{\mathrm{S}_{\mathrm{H}}} & =\frac{1}{\sqrt{2 \pi} \sigma} \int_{-\infty}^{\sqrt[2]{\frac{\sqrt{E s}}{10}}} \mathrm{e}^{\frac{\left(z-3 \sqrt[3]{\frac{E s}{10}}\right)^{2}}{2 \sigma^{2}}} \mathrm{dz} \\
& =\frac{1}{2} \operatorname{erfc}\left(\sqrt{\frac{\mathrm{Es}}{10 \mathrm{n} 0}}\right)
\end{aligned}
$$

Vertically (PDF): We compute $\mathrm{P}_{\mathrm{s}_{\mathrm{v}}}$ at $\mathrm{S}_{3}$ as follows:

$$
\begin{aligned}
P_{S_{\mathrm{V}}} & =\frac{1}{\sqrt{2 \pi} \sigma} \int_{-\infty}^{\sqrt[2]{\frac{E s}{10}}} \mathrm{e}^{\frac{\left(z-3 \cdot 3 \frac{\sqrt{\frac{E s}{10}}}{20}\right.}{2 \sigma^{2}}} \mathrm{dz} \\
& =\frac{1}{2} \operatorname{erfc}\left(\sqrt{\frac{\mathrm{Es}}{10 \mathrm{n} 0}}\right)
\end{aligned}
$$

By calculating $\mathrm{P}_{\mathrm{C}}$ and neglecting the smallest term at higher values of $\mathrm{Es} / \mathrm{n} 0$, the error symbols probability for Symbol $\mathrm{S}_{3}$ became:

$$
P_{S}=\operatorname{erfc}\left(\sqrt{\frac{E s}{10 \mathrm{n} 0}}\right)
$$

Assuming that all symbols at the same group are equally likely, $4 / 16$ four symbols in the interior small square $\left(\mathrm{S}_{5}\right.$ group), $4 / 16$ four symbols in the outer big 


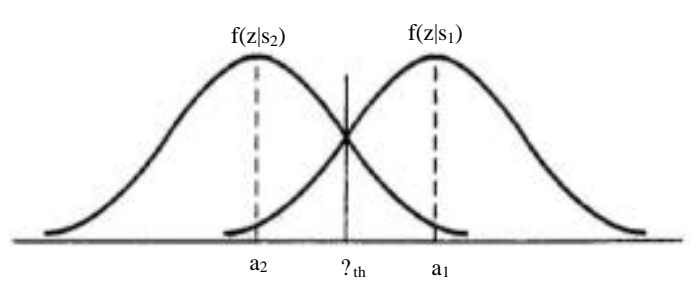

Fig. 6: Conditional PDF

square ( $\mathrm{S}_{3}$ group), 8/16 eight Symbols at the circular $\left(\mathrm{S}_{11}\right.$ group), then, the total probability of symbols error is expressed as:

$$
\begin{aligned}
& \mathrm{P}_{\mathrm{S}}=\frac{4}{16} * 2 \operatorname{erfc}\left(\sqrt{\frac{\mathrm{Es}}{10 \mathrm{n} 0}}\right)+\frac{4}{16} * \operatorname{erfc}\left(\sqrt{\frac{\mathrm{Es}}{10 \mathrm{n} 0}}\right)+ \\
& \quad \frac{8}{16} * \frac{3}{2} \operatorname{erfc}\left(\sqrt{\frac{\mathrm{Es}}{10 \mathrm{n} 0}}\right) \\
& =\frac{3}{2} \operatorname{erfc}\left(\sqrt{\frac{\mathrm{Es}}{10 \mathrm{n} 0}}\right)
\end{aligned}
$$

Analysis 16QAM shifted by d: For the symbol $\mathrm{S}_{3}$ (big square symbols group), $\mathrm{S}_{5}$ (small square symbols group) and $\mathrm{S}_{11}$ (circle symbols group) as shown in Fig. 2 , the symbol error rate after shifting for symbols mention above calculating accordance the probability of error with Gaussian noise in horizontal and vertical direction which the PDF of it illustrated in Fig. 6. Because all symbols are equally likely (equal probability) then the threshold value ${ }_{\text {th }}$ represented by equation below is an optimum value to minimize the error of probability (Hsu, 2002):

$$
\lambda_{\mathrm{th}}=\frac{\mathrm{a}_{1}+\mathrm{a}_{2}}{2}
$$

First: The symbol error probability for $\mathrm{S}_{3}$ symbol after shifted the outer vertical symbols by $d$ value.

Horizontal (PDF): We calculate $\mathrm{P}_{\mathrm{S}_{\mathrm{I}}}$ after shifting as below:

$$
\begin{aligned}
\mathrm{a}_{1} & =3 \sqrt{\frac{\mathrm{Es}}{10}}-\mathrm{d}, \mathrm{a}_{2}=\sqrt{\frac{\mathrm{Es}}{10}} \\
\mathrm{P}_{\mathrm{S}_{\mathrm{H}}} & =\frac{1}{\sqrt{2 \pi} \sigma} \int_{-\infty}^{\mathrm{th}_{\mathrm{Hh}}} \mathrm{e}^{\frac{\left(z \cdot\left(\sqrt[3]{\frac{\mathrm{Es}}{10}} \mathrm{~d}\right)\right)^{2}}{2 \sigma^{2}} \mathrm{dz}} \\
& =\frac{1}{2} \operatorname{erfc}\left(\sqrt{\left.\frac{\mathrm{Es}}{10 \mathrm{n} 0}-\frac{1}{2 \sqrt{\mathrm{n} 0}} \mathrm{~d}\right)}\right.
\end{aligned}
$$

Vertical (PDF): We calculate $P_{s_{v}}$ after shifting. The $P_{s_{v}}$ for $\mathrm{S}_{3}$ is not change after shifting and kept the same as in the standard state analysis:

$$
\mathrm{P}_{\mathrm{S}_{\mathrm{V}}}=\frac{1}{2} \operatorname{erfc}\left(\sqrt{\frac{\mathrm{Es}}{10 \mathrm{n} 0}}\right)
$$

After approximation the final term in $\mathrm{P}_{C}$ equation is written as:

$$
\mathrm{P}_{\mathrm{C}}=\mathrm{P}_{\mathrm{C}_{\mathrm{H}}} * \mathrm{P}_{\mathrm{C}_{\mathrm{V}}}=\left(1-\mathrm{P}_{\mathrm{S}_{\mathrm{H}}}\right) *\left(1-\mathrm{P}_{\mathrm{S}_{\mathrm{V}}}\right)
$$

The total $\mathrm{P}_{\mathrm{S}}$ for symbol $\mathrm{S}_{3}$ is expressed as:

$$
\mathrm{P}_{\mathrm{S}}=\frac{1}{2} \operatorname{erfc}\left(\sqrt{\frac{\mathrm{Es}}{10 \mathrm{n} 0}}\right)+\frac{1}{2} \operatorname{erfc}\left(\sqrt{\frac{\mathrm{Es}}{10 \mathrm{n} 0}}-\frac{1}{2 \sqrt{\mathrm{n} 0}} \mathrm{~d}\right)
$$

Second: The symbol error probability for $\mathrm{S}_{11}$ after shifting outer vertical symbols.

\section{Horizontally (PDF):}

$$
\mathrm{P}_{\mathrm{S}_{\mathrm{H}}}=\frac{1}{2} \operatorname{erfc}\left(\sqrt{\frac{\mathrm{Es}}{10 \mathrm{n} 0}}-\frac{1}{2 \sqrt{\mathrm{n} 0}} \mathrm{~d}\right)
$$

Vertically (PDF): The $P_{s_{v}}$ for $S_{11}$ is not changed after shifting and kept the same as in the standard state analysis:

$$
\mathrm{P}_{\mathrm{S}_{\mathrm{V}}}=\operatorname{erfc}\left(\sqrt{\frac{\mathrm{Es}}{10 \mathrm{n} 0}}\right)
$$

The total symbol error probability for $\mathrm{S}_{11}$ symbol is:

$$
\mathrm{P}_{\mathrm{S}}=\operatorname{erfc}\left(\sqrt{\frac{\mathrm{Es}}{10 \mathrm{n} 0}}\right)+\frac{1}{2} \operatorname{erfc}\left(\sqrt{\frac{\mathrm{Es}}{10 \mathrm{n} 0}}-\frac{1}{2 \sqrt{\mathrm{n} 0}} \mathrm{~d}\right)
$$

The total probability of error for 16QAM after shiftingthe outer symbols by $\mathrm{d}$ distance to the inside is written as:

$$
\mathrm{P}_{\mathrm{S}_{\text {total }}}=\mathrm{P}_{\substack{\mathrm{S}_{\text {small }} \\ \text { square }}}+\mathrm{P}_{\mathrm{S}_{\text {biquare }}}+\mathrm{P}_{\mathrm{S}_{\text {cick }}}
$$

$\mathrm{P}_{\mathrm{S}}$ for small square ( $\mathrm{S}_{5}$ group):

$$
\mathrm{P}_{\mathrm{S}}=\frac{4}{16} * 2 \operatorname{erfc}\left(\sqrt{\frac{\mathrm{Es}}{10 \mathrm{n} 0}}\right)
$$

$\mathrm{P}_{\mathrm{S}}$ for big square $\left(\mathrm{S}_{3}\right.$ group): 


$$
\mathrm{P}_{\mathrm{S}}=\frac{4}{16} *\left[\frac{1}{2} \operatorname{erfc}\left(\sqrt{\frac{\mathrm{Es}}{10 \mathrm{n} 0}}\right)+\frac{1}{2} \operatorname{erfc}\left(\sqrt{\frac{\mathrm{Es}}{10 \mathrm{n} 0}}-\frac{1}{2 \sqrt{\mathrm{n} 0}} \mathrm{~d}\right)\right]
$$

$\mathbf{P}_{\mathrm{s}}$ for symbols around the circle: The symbol error probability after shifting for eight symbols around the circle must different when comparing them with standard symbol constellation, four symbols from eight $\left(\mathrm{S}_{4}, \mathrm{~S}_{7}, \mathrm{~S}_{8}\right.$, $\mathrm{S}_{11}$ ) are shifted where the other symbols do not have an effect:

$$
\begin{aligned}
\mathrm{P}_{\mathrm{S}}= & \frac{4}{16} * \frac{3}{2} \operatorname{erfc}\left(\sqrt{\frac{\mathrm{Es}}{10 \mathrm{n} 0}}\right)+\frac{4}{16} * \\
& {\left[\operatorname{erfc}\left(\sqrt{\frac{\mathrm{Es}}{10 \mathrm{n} 0}}\right)+\frac{1}{2} \operatorname{erfc}\left(\sqrt{\frac{\mathrm{Es}}{10 \mathrm{n} 0}-\frac{1}{2 \sqrt{\mathrm{n} 0}} \mathrm{~d}}\right)\right] }
\end{aligned}
$$

Then, the total probability of error (symbol error rate) with shifting is written as:

$$
\mathrm{P}_{\mathrm{S}}=\frac{5}{4} * \operatorname{erfc}\left(\sqrt{\frac{\mathrm{Es}}{10 \mathrm{n} 0}}\right)+\frac{1}{4} * \operatorname{erfc}\left(\sqrt{\frac{\mathrm{Es}}{10 \mathrm{n} 0}}-\frac{1}{2 \sqrt{\mathrm{n} 0}} \mathrm{~d}\right)
$$

For 16QAM the relation between the energy of symbol and the energy of bit as shown below:

$$
\begin{aligned}
& \mathrm{E}_{\mathrm{S}}=\mathrm{k} * \mathrm{E}_{\mathrm{b}}, \mathrm{k}=\log 2(16), \mathrm{E}_{\mathrm{S}}=4 * \mathrm{E}_{\mathrm{b}} \\
& \mathrm{d}=\mathrm{d}^{\prime} * \sqrt{\frac{\mathrm{Es}}{10}}=\mathrm{d}^{\prime} * \sqrt{\frac{2 * \mathrm{~Eb}}{5}}
\end{aligned}
$$

where $d \bullet$ is the shifting factor, its values range:

$$
0 \leq \mathrm{d}^{\prime} \leq 1
$$

The final equation of symbol error rate for 16QAM shifted by $\mathrm{d} \cdot$ shown below:

$$
\mathrm{P}_{\mathrm{S}}=\frac{5}{4} * \operatorname{erfc}\left(\sqrt{\frac{2}{5} \frac{\mathrm{Eb}}{\mathrm{n} 0}}\right)+\frac{1}{4} * \operatorname{erfc}\left(\left(1-0.5 * \mathrm{~d}^{\prime}\right) \sqrt{\frac{2}{5} \frac{\mathrm{Eb}}{\mathrm{n} 0}}\right)
$$

\section{RESULTS AND DISCUSSION}

For the purpose of comparison between theoretical analysis and simulation in this study use MATLAB to simulate the performance of 16QAM (Gopi, 2015; Mathuranathan, 2018), compute symbol error rates and plots them against the theoretical symbol error rates to show the matching between curves for any value of $\mathrm{d}$ - and obtained the symbol error rates at

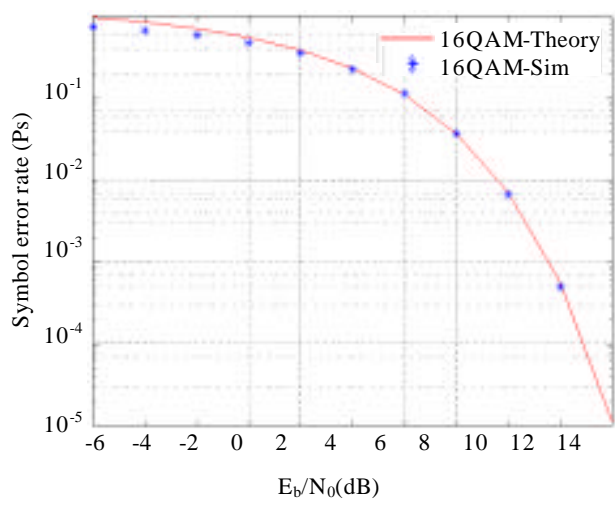

Fig. 7: Theory and simulation curves for $16 \mathrm{QAM}$ symbol error rate with over AWGN, $d \bullet=0$

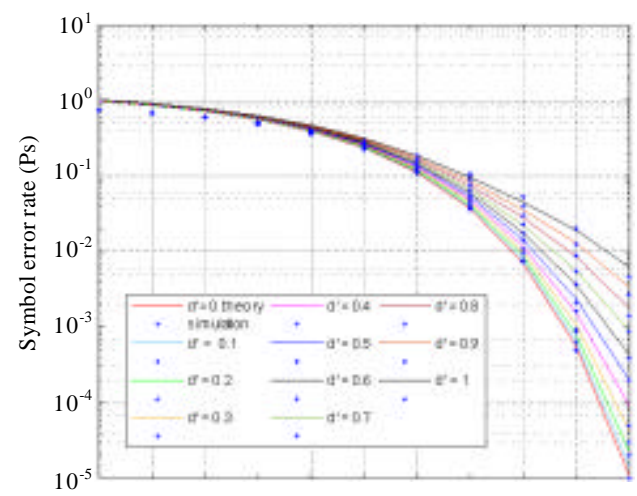

Fig. 8: Theory and simulation curves for 16QAM symbol error rate with AWGN, $0=\mathrm{d} \bullet=1$

that value. When choosing $\mathrm{d} \cdot=0$, this means no shifting and the standard curve depicted as shown in the Fig. 7 .

For d' values from zero to one the value of symbol error rate increases with the increase in $\mathrm{d}^{\prime}$ as shown in Fig. 8. For d• values such as the set $(0,0.2,0.4$, $0.6,0.8)$, we can observe from the simulation in Fig. 8 and 9 that the matching is exact between the theoretical and simulation curves with little deflection at high $\mathrm{E}_{\mathrm{b}} / \mathrm{N}_{0}$ above $13 \mathrm{~dB}$ due to approximation in the theoretical analysis.

The symbol error rate at $E_{b} / N_{0}=12 \mathrm{~dB}$ for d' set values $(0,0.2,0.4,0.6,0.8)$ is increased by $(0.00040 .00090 .00150 .00360 .0086)$, respectively when increasing d' because the symbols at the vertical position border become more closest to another symbol.

When points at the vertical output boundaries of the constellation are moved inside by $\mathrm{d} \bullet$ then the voltage for 
J. Eng. Applied Sci., 14 (Special Issue 6): 9424-9430, 2019

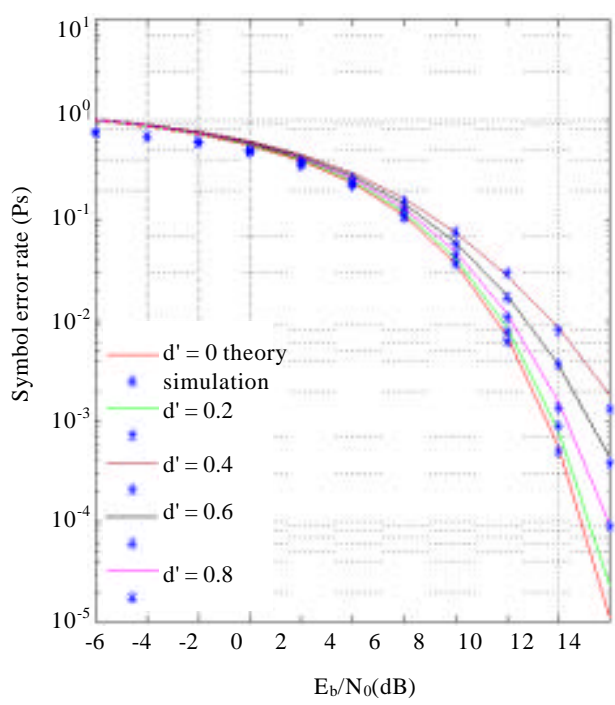

Fig. 9: The theory and simulation curves to symbol error rate at $\left(d^{\prime}=0,0.2,0.4,0.6,0.8\right)$

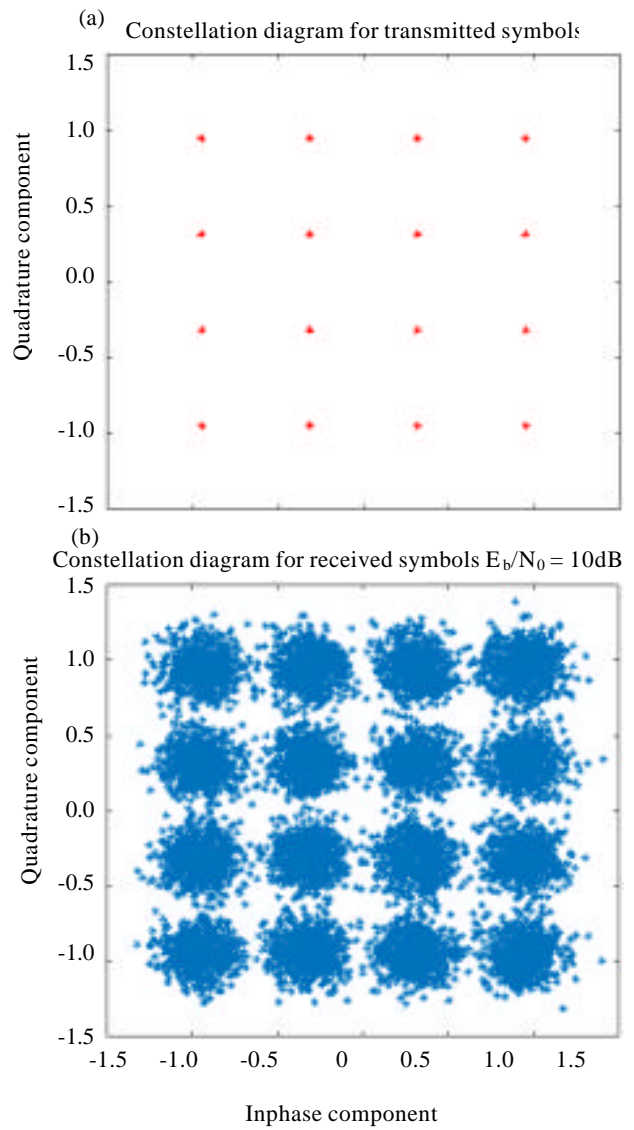

Fig. 10: Constellation diagram for transmitted and Received symbols, $\mathrm{E}_{\mathrm{b}} / \mathrm{N}_{0}=10 \mathrm{~dB}, \mathrm{P}_{\mathrm{S}}=0.00643$, $\mathrm{d}^{\prime}=0$

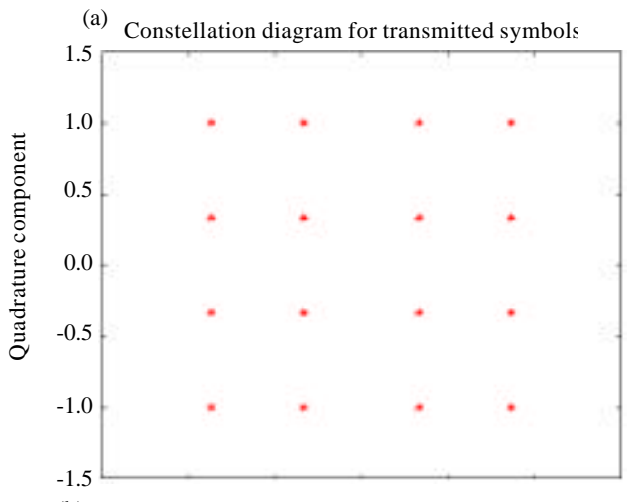

(b)

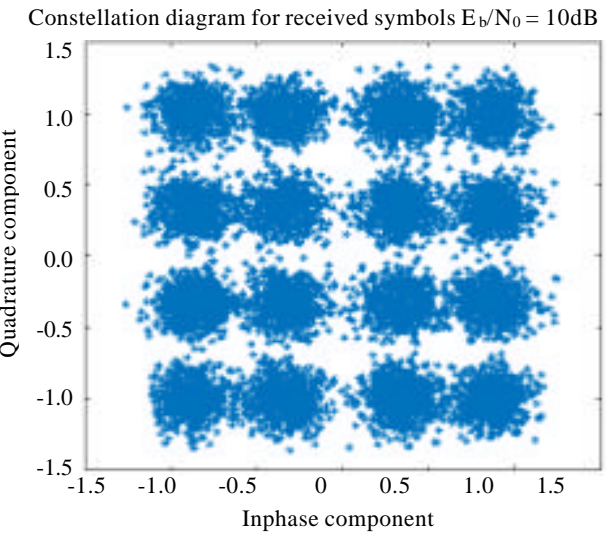

Fig. 11: Constellation diagram for transmitted and received symbols, $\mathrm{E}_{\mathrm{b}} / \mathrm{N}_{0}=10 \mathrm{~dB}, \mathrm{P}_{\mathrm{S}}=0.01176$, $\mathrm{d}^{\prime}=0.4$

Table 1: The effect of shifting on average power

\begin{tabular}{lll}
\hline $\mathrm{d} \bullet$ & $\mathrm{A}$ & $\mathrm{P}_{\mathrm{av}}=\mathrm{A}^{*} \mathrm{P}_{\mathrm{aV}}$ \\
\hline 0 & 1 & 10 \\
0.1 & 0.9705 & 9.705 \\
0.2 & 0.9420 & 9.420 \\
0.3 & 0.9145 & 9.145 \\
0.4 & 0.8880 & 8.880 \\
0.5 & 0.8625 & 8.625 \\
0.6 & 0.8380 & 8.380 \\
0.7 & 0.8145 & 8.145 \\
0.8 & 0.7920 & 7.920 \\
0.9 & 0.7705 & 7.705 \\
1 & 0.7500 & 7.500 \\
\hline
\end{tabular}

new constellation at that value is reduced and their average power reduced by a factor $\mathrm{A}$ where:

$$
A=0.05 * d^{\prime 2}-0.3 * d^{\prime}+1
$$

The average power reduction factor for different values of d' and average power for shifting constellation $\mathrm{P}^{\prime}{ }_{\text {av }}$ which is equal the average power for standard constellation $\mathrm{P}_{a v}($ at $\mathrm{d} \bullet=0)$ is multiplied by reduction factor A as shown in Table 1 (Fig. 11). 


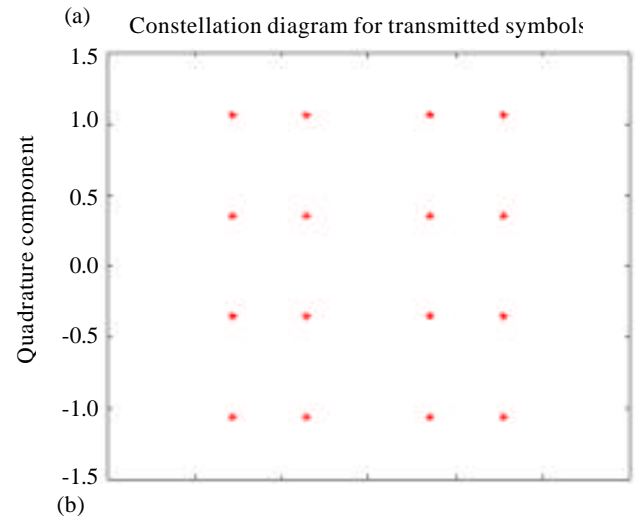

Constellation diagram for received symbols $\mathrm{E}_{\mathrm{b}} / \mathrm{N}_{0}=10 \mathrm{~dB}$

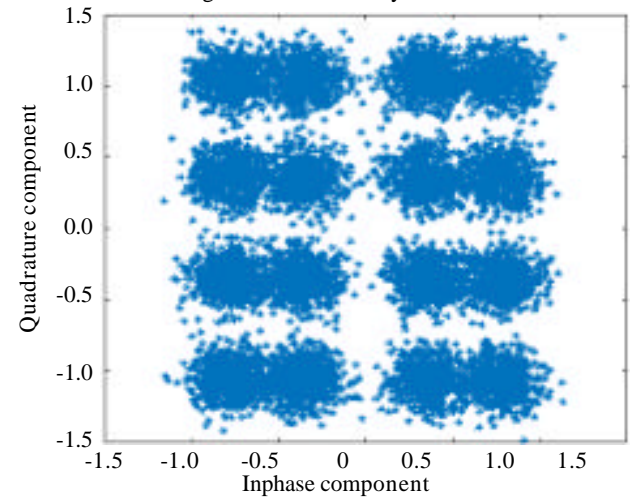

Fig. 12: Constellation diagram for transmitted and received symbols, $E_{b} N_{0}=10 \mathrm{~dB}, P_{S}=0.02826$, $\mathrm{d}^{\prime}=0.8$

The constellation diagram for transmitted and received symbols, the symbols error rate at d' $(0,0.4,0.8)$ and $E_{b} / N_{0}=10 \mathrm{~dB}$ is shown in Fig. (10-12), respectively.

\section{CONCLUSION}

The effect of shifting on symbol error rate and average power has been computed and studied.

\section{REFERENCES}

Bateman, A., 1999. Digital Communications: Design for the Real World. Addison-Wesley Longman Limited, New York, USA.,

Cahn, C., 1960. Combined digital phase and amplitude modulation communication systems. IRE. Trans. Commun. Syst., 8: 150-155.

Chen, J., 2004. Carrier recovery in burst-mode 16QAM. Ph.D Thesis, The Department of Electrical Engineering, University of Saskatchewan Saskatoon, Saskatchewan, Canada.

Glover, I.A. and P.M. Grant, 2010. Digital Communication. 3rd Edn., Prentice Hall, London, UK.,.

Gopi, E.S., 2015. Digital Signal Processing for Wireless Communication using Matlab. Springer, Berlin, Germany, ISBN:9783319206516, Pages: 174.

Hancock, J. and R. Lucky, 1960. Performance of combined amplitude and phase-modulated communication systems. IRE. Trans. Commun. Syst., 8: 232-237.

Hsu, H.P., 2002. Analog and Digital Communication (Schaums Outlines). 2nd Edn., McGraw-Hill, New York, USA., ISBN:13-978-0071402286, Pages: 336.

Mathuranathan, V., 2018. Wireless Communication Systems in MATLAB. Independent Publishing Industry, USA., ISBN:13-9781720114352, Pages: 358. 